\section{Field and Detached-fruit Screening Tests for Resistance to Belly Rot in Cucumber}

\author{
Todd C. Wehner ${ }^{1}$, Nischit V. Shetty ${ }^{2}$, and Joseph T. Sloane ${ }^{2}$ \\ Department of Horticultural Science, North Carolina State University, Raleigh, \\ NC 27695-7609
}

\begin{abstract}
Additional index words. fruit rot, Cucumis sativus, disease, resistance, Rhizoctonia solani, Pseudomonas sp., Laetisaria sp., Trichoderma harzianum, vegetable breeding
\end{abstract}

\begin{abstract}
Field and detached-fruit screening tests were developed for evaluating cucumber (Cucumis sativus L.) plant introduction accessions, breeding lines, and cultivars (hereafter collectively referred to as cultigens) for resistance to fruit rot caused by Rhizoctonia solani Kuhn. The factors that were examined for developing a detached-fruit test were five inoculum levels of $R$. solani AG-4 and two cover treatments. The major influence on disease reaction was inoculum level. The best method used 50 -mm-diameter fruit placed on sterile soil inoculated with 6400 oat grains $/ \mathrm{m}^{2}$ colonized with $R$. solani and watered initially, then misted every 3 days for 1 minute, left uncovered, and rated after 10 days for the percentage of the fruit surface covered with lesions. Field and detached-fruit tests were conducted using two different inoculum levels of $R$. solani ( 3200 and 4800 oat grains $/ \mathbf{m}^{2}$ ). The four most resistant cultigens, based on the results of field and detached-fruit tests, were PI 163216, PI 197088, PI 357852, and PI 280096. One field and detached-fruit test pair was not significantly correlated (detached-fruit screening test one vs. field screening test one), but the other (detached-fruit test two vs. field screening test two) was correlated $(r=0.50)$. The detached-fruit test could be used for general classification of resistance or susceptibility. Resistant cultigens could be identified with either method, but the field test had slightly lower coefficients of variation.
\end{abstract}

Belly rot caused by Rhizoctonia solani Kuhn is a serious disease of cucumber $(\mathrm{Cucu}$ mis sativus L.), and limits production in warm humid areas of the United States. Belly rot reduced cucumber yield by an average of $7 \%$ to 9\% in the southern United States (Sumner and Smittle, 1976). Under optimal conditions for the pathogen, losses as high as $80 \%$ reduction in yield were reported (Lewis and Papavizas, 1980). The belly rot fungus was estimated to be present in $72 \%$ of all North Carolina cucumber fields (St. Amand and Wehner, 1991). In addition to direct loss in yield from the disease, additional costs also are incurred in removing diseased fruit after harvest, and the quality of the packed product is reduced when diseased fruit are accidentally processed.

Seven anastomosis groups (AG) of $R$. solani have been reported throughout the world (Bolkan and Ribeiro, 1985). R. solani AG-4 is known to attack cucumber (Ellis, 1951; Jenkins and Averre, 1981). Warm and humid conditions are optimum for the pathogen. Disease incidence is increased by monoculture, highdensity planting, and mechanical harvesting procedures. Warm, moist conditions in a dense canopy contribute to increased disease inci-

Received for publication 11 Jan. 2002. Accepted for publication $4 \mathrm{Feb}$. 2003. The use of trade names in this publication does not imply endorsement by the Agricultural Service of products named, or criticism of similar ones not mentioned. We gratefully acknowledge the technical assistance of R.R. Horton, Jr.

${ }^{1}$ Professor; to whom reprint requests should be addressed (todd_wehner@ncsu.edu).

${ }^{2}$ Graduate Assistant. dence. The typical symptoms of belly rot are sunken, brown, necrotic lesions, which often develop into a hard, corky layer (Jenkins and Averre, 1981). Those symptoms can appear on apparently healthy fruit in as little as $24 \mathrm{~h}$. Blemishes on the fruit result in an unmarketable product.

Control of fruit rot using chemicals like chlorothalonil (tetrachloroisopthalonitrile), captafol $\{$ cis- $N$-[(1,1,2,2-tetrachloroethyl) thio]-4-cyclohexene-1,2-dicarboximide $\}$, $\mathrm{NaN}_{3}$, and folpet $\{N-[($ trichloromethyl) thio $]$ phthalimide\} have been reported (Sumner and Smittle, 1976). Halterlein et al. (1981) reported that paraquat $\left(1,1^{\prime}\right.$-dimethy- $4,4^{\prime}$ bipyridinium dichloride), a plant dessicant when applied at a rate of $0.036 \mathrm{~kg} \cdot \mathrm{ha}^{-1}$ at the first flower stage reduced the incidence of cucumber fruit rot by $47 \%$. Kucharek and Cullen (1989) recommended the use of a single preemergent spray of Flutolanil $50 \mathrm{WP}$ (generic) at the rate of $4.48 \mathrm{~kg} \cdot \mathrm{ha}^{-1}$ for effective control of fruit rot caused by $R$. solani. Apart from chemical control, solarization of the soil for 5 to 6 weeks using clear polyethylene has also been shown to reduce the levels of $R$. solani in the soil (Keinath, 1995). Biological control of $R$. solani using Pseudomonas sp. (De Freitas and Germida, 1991; Fridlender et al., 1993), Laetisaria sp. (Lewis and Papavizas, 1992), Trichoderma harzianum at rates of $200 \mathrm{~kg} \cdot \mathrm{ha}^{-1}$ (Lewis and Papavizas, 1980) and binucleate rhizoctonia (BNR) (Cubeta and Echandi, 1991; Villajuan-Abgona et al., 1996) has been reported. Plowing fields to a depth of 0.20 to $0.25 \mathrm{~m}$ before planting has also been suggested as a method of cultural control (Lewis and Papavizas, 1980). However, because $R$. solani is a soil inhabitant, it quickly reestablishes in cucumber fields regardless of the control methods used (Lewis et al., 1979; Parmeter, 1970).

All current cultivars of pickling cucumber grown in the United States are susceptible to belly rot. High-level, single-gene resistance to the pathogen has been identified using a detached-fruit test, but all resistant accessions identified so far have brown, netted skin. That trait makes them unusable for the American market. The heritability of resistance to $R$. solani was estimated at 0.24 (low to moderate) (Sloane et al., 1985; Sloane and Wehner, 1984). Thus, resistance to the pathogen can be transferred to horticulturally acceptable material using a good source of resistant germplasm and reliable testing methods. Booy et al. (1987) reported that cucumber cultigens that were resistant to damping off were not resistant to fruit $\operatorname{rot}(r=-0.19$ to -0.10$)$. Genetic resistance would be an economical and environmentally safe method of control if a source of resistance were found. Wehner and Palmer (1987) reported a seedling test for resistance to belly rot. Adetached-fruit test having a high correlation with belly rot field test results would be advantageous in permitting off-season testing, would use less inoculum, and reduce the spread of the pathogen in fields.

The objective of these tests was to develop an optimum method of screening cucumber germplasm for resistance to belly rot, and to identify sources of resistance to the pathogen.

\section{Materials and Methods}

Two methods tests and three screening tests were run. The methods tests were to develop a detached-fruit test for cucumber cultigens. The detached-fruit tests were run in a mist chamber in the greenhouse where temperatures ranged from $22{ }^{\circ} \mathrm{C}$ at night to $34{ }^{\circ} \mathrm{C}$ during the day. The tests used 50-mm-diameter fruit (same size as used in the field test) that were placed on inoculated soil in flats. The rationale for testing 50-mm-diameter fruit in the field was that those fruit had the longest time in contact with the pathogen-infested soil, and, therefore, the greatest opportunity for infection. For detached-fruit tests, small diameter fruit tended to dry up and shrivel rapidly, making it difficult to observe belly rot lesions. However, optimum fruit size should be evaluated in future tests.

Inoculum. Four isolates of $R$. solani were used in the initial screening test. Isolates were maintained at the Dept. of Plant Pathology, North Carolina State Univ, Raleigh, N.C. All were in anastomosis group AG-4. The isolates were tested for pathogenicity and then maintained on acidified potato dextrose agar (PDA) (Tuite, 1969). Inoculum was increased by placing $1-\mathrm{cm}^{2}$ colonized pieces of acidified PDA into autoclavable bags containing $300 \mathrm{~mL}$ of oat grains and $200 \mathrm{~mL}$ of tap water. The oat grains and water had been previously autoclaved twice in the bags at a 24-h interval. In screening test one, the inoculum consisted of an equal mix of four isolates. In screening test two, the inoculum consisted of a mix of 
16 isolates: the 12 North Carolina isolates, plus the four used in screening test one.

\section{Method tests for detached fruit}

Methods test one (detached fruit). Fruit of cultivars Calypso, Carolina, Lucky Strike, and Score were harvested from field plots at Clinton, N.C. Plastic flats $(450 \times 520 \mathrm{~mm})$ were filled to a depth of $\approx 50 \mathrm{~mm}$ with steam-sterilized field soil (Norfolk-Ruston sandy loam). Oat grains colonized by $R$. solani were added to the soil surface at the rate of $0,800,1600$, 3200 , or 6400 oat grains $/ \mathrm{m}^{2}$ (estimated by weight) for the five treatments, respectively. Fruit of the four cultivars were placed randomly on flats, each containing one of the five inoculum treatments, and covered with newspaper or left uncovered. The experiment had a factorial treatment arrangement in a randomized complete block with five inoculum levels, two cover treatments, four cultivars, and two replications. Flats were watered lightly as needed to keep the soil surface moist. Fruit were rated on the $3 \mathrm{rd}, 6$ th, 8 th, and 11th days after inoculation for number of lesions and percentage of total fruit surface infected.

Methods test two (detached fruit). The test was conducted using the pickling cucumber cultivars Calypso, Lucky Strike, Pioneer, Pikmaster, and Sumter, and the slicing cucumber cultivars Dasher, Cypress, Revenue, Sprint 440, and Verino. Fruit were harvested from field plots at Clinton, N.C. The same technique was used in preparation of plastic flats except that inoculum treatments of $0,1600,3200,6400$, or 12800 oat grains $/ \mathrm{m}^{2}$ were used. Fruit of each of the 10 cultivars were randomly placed in flats, each containing one of the five inoculum treatments, and which were then placed under mist shelves. The experiment was a split plot treatment arrangement in a randomized complete-block design with five inoculum levels, 10 cultivars, and three replications. Mist was applied every $3 \mathrm{~d}$ for $1 \mathrm{~min}$. Fruit were rated on the 7 th, 9 th, and 11 th days after inoculation for the number of lesions and percentage of total fruit surface infected.

\section{Germplasm screening tests}

The initial screening was conducted using 1063 cucumber cultigens (720 plant introduction accessions from the U.S. Dept. of Agriculture Regional Plant Introduction Station at Ames, Iowa, and 343 cultivars and breeding lines from the North Carolina State Univ. breeding program). It was an unreplicated experiment using one fruit per cultigen. Fruit were placed on greenhouse beds inoculated with $R$. solani at the rate of 1600 oat grains/ $\mathrm{m}^{2}$. The test was designed to provide a rough identification of cultigens that could be used for further development of testing methods.

Screening test one (detached fruit). Seeds of the most resistant and most susceptible cultigens (totaling 174) were planted in 1.5 $\times 1.5-\mathrm{m}$ plots separated by $1.5-\mathrm{m}$ alleys at Clayton, N.C. Fruit with a diameter of $\approx 50$ $\mathrm{mm}$ and free of lesions, were harvested and placed in flats in a mist chamber. Plastic flats were prepared as described above and inoculated at the rate of 3200 oat grains $/ \mathrm{m}^{2}$ colonized with $R$. solani. Flats were then watered thoroughly and covered with newspaper. The soil surface was kept moist by daily misting. Temperatures in the greenhouse mist chamber ranged from $24^{\circ} \mathrm{C}$ at night to $33^{\circ} \mathrm{C}$ during the day. After $10 \mathrm{~d}$, fruit were rated individually for the number of lesions and the percentage of the total fruit surface infected. The experiment was a completely random design with three replications.

Screening test two (detached fruit). The above experiment was repeated with 149 cultigens. Those were planted in $1.2 \times 1.5-\mathrm{m}$ plots with $0.3-\mathrm{m}$ alleys at Clayton, N.C. Fruit free of lesions were harvested, and placed in flats in the mist chamber as described above. The inoculum concentration was 4800 oat grains $/ \mathrm{m}^{2}$ colonized with $R$. solani. Flats were then watered thoroughly and placed in the mist chamber as described above. The flats were misted every $3 \mathrm{~d}$ for $1 \mathrm{~min}$. After 7 and $10 \mathrm{~d}$ in the mist chamber, the fruit were rated individually for number of lesions and percentage of fruit surface covered as described above. The experiment was a completely random design with three replications.

Screening test one (field). The 174 cultigens in screening test one also were tested in the field. Cultural practices were as described for the initial screening test. Seeds were planted on raised, shaped beds with $0.5-\mathrm{m}$ tops in plots $1.5 \mathrm{~m}$ long, and $1.5 \mathrm{~m}$ apart (center to center) at Clinton, N.C. The plots were inoculated with 3200 oat grains $/ \mathrm{m}^{2}$ colonized with $R$. solani at the vine tip-over stage. The soil surface in the field plots was raked to help incorporate the inoculum, which was then applied by hand to cover the soil surface.

Fruit $\approx 50 \mathrm{~mm}$ in diameter were rated for number of lesions and percentage of the fruit surface infected. Ratings were made on individual fruit selected randomly from each plot at 19, 24, 30, and $34 \mathrm{~d}$ after inoculation. The experiment was a randomized complete-block design with 174 cultigens, two replications, and four rating dates.

Screening test two (field). Screening test two was similar to screening test one, except that only 149 cultigens were used (the same ones as in methods test two). At the vine tip-over stage, plants were inoculated at the rate of 4800 oat grains $/ \mathrm{m}^{2}$ colonized with $R$. solani. Cucumber fruit with a diameter of $\approx 50 \mathrm{~mm}$ were rated for the same traits as in the previous tests. Prior to the first rating, all fruit in a given plot were inspected, and flags were placed at the peduncle end of the two most heavily infected fruit (on the basis of percentage of surface infected). Those two fruit were used for each rating. After the rating was completed, any plots that continuously rated $0 \%$ or $1 \%$ infection were again inspected to ensure that no diseased fruit had been overlooked. Ratings were made at $25,32,39$, and $46 \mathrm{~d}$ after inoculation. The experiment was a randomized complete-block design with 149 cultigens, two replications, and four rating dates.

Data analysis. Data for all experiments were analyzed using the GLM and CORR procedures of SAS (SAS Institute, Cary, N.C.).

\section{Results and Discussion}

In the two tests for development of a detached-fruit testing method, individual fruit of each cultivar were evaluated. Lesions were verified to be caused by $R$. solani. Individual fruit ratings ranged from $0 \%$ to $40 \%$ of the fruit surface damaged (Table 1). The cultivar means ranged from $1.8 \%$ to $24.0 \%$ on the inoculated soil treatments. There was no significant difference between covered and uncovered flats (data not shown). The major influence on disease reaction was inoculum concentration.

Soil moisture was not critical as long as the soil and inoculum were not allowed to dry. Inoculum concentration in the range of 3200 to 6400 oat grains $/ \mathrm{m}^{2}$ provided best results, with a rate of 5400 oat grains $/ \mathrm{m}^{2}$ causing a range in cultivar means of $0 \%$ to $30 \%$ damage of the fruit surface. A damage percentage of 30\% indicated that the entire "belly" (fruit surface contacting the soil) was rotted on the average fruit of the cultivar tested. At low inoculum concentrations, the fruit rotted from secondary pathogens before $R$. solani lesions formed. When high concentrations of the inoculum were used, the differences among cultigens were less. At the temperatures used in this test, $10 \mathrm{~d}$ was the longest that fruit could be left on the soil before rating because of the rotting caused by secondary pathogens. The secondary pathogens appeared to be Pythium sp., and probably could be controlled by dipping the fruit in a $10 \%$ chlorine bleach solution followed by a water rinse before placing on the inoculated soil.

The detached-fruit testing method that provided the best results (greatest range of cultigen means from resistant to susceptible)

Table 1. Mean, range, and standard error (SE) of the mean for percentage of fruit surface damaged after inoculation of detached-fruit cucumber method test with Rhizoctonia solani.

\begin{tabular}{lccc}
\hline $\begin{array}{l}\text { Inoculum } \\
\text { concn }^{z}\end{array}$ & Mean & Range & SE \\
\hline \multicolumn{4}{c}{ Methods test $1^{y}$} \\
0 & 0.0 & $0-0$ & 0.0 \\
800 & 4.4 & $0-15$ & 2.1 \\
1600 & 6.9 & $0-26$ & 2.0 \\
3200 & 11.9 & $0-35$ & 2.6 \\
6400 & 15.4 & $0-35$ & 2.3 \\
\multicolumn{4}{c}{ Methods test $2^{x}$} \\
0 & 0.0 & $0-0$ & 0.0 \\
1600 & 1.8 & $0-5$ & 0.6 \\
3200 & 9.6 & $0-18$ & 1.9 \\
6400 & 15.0 & $6-30$ & 3.0 \\
12800 & 24.0 & $10-40$ & 3.1 \\
\hline
\end{tabular}

${ }^{\mathrm{z}}$ Values are oat grains $/ \mathrm{m}^{2}$ colonized with $R$. solani of soil.

'Cultivars tested were 'Calypso', 'Score', 'Lucky Strike', 'Carolina', and 'Pikmaster'.

'Cultivars tested were 'Calypso', 'Sumter', 'Lucky Strike', 'Pioneer', and 'Pikmaster' pickling cucumbers and 'Dasher', 'Verino', 'Revenue', 'Sprint 440', and 'Cypress' fresh-market cucumbers. Data are means of two replications in each of 2 years. Ranges and SE are among cultivar means. Fruit were rated $10 \mathrm{~d}$ after inoculation. 
was as follows: place 50-mm-diameter fruit on sterile soil inoculated with 6400 oat grains $/ \mathrm{m}^{2}$ colonized with $R$. solani and watered initially, then mist every $3 \mathrm{~d}$ for $1 \mathrm{~min}$, leave uncovered, and rate after $10 \mathrm{~d}$ for the percentage of the fruit surface covered with belly rot lesions.

The four most resistant cultigens, based on the results of the initial screening test and screening tests one and two (field and detached-fruit), were PI 163216, PI 197088, PI 357852, and PI 280096 (Table 2). Those cultigens showed resistance in all of the experiments where data were obtained. Data for some of the cultigens were not obtained in some experiments. It is unlikely that the cultigens with ratings of $0 \%$ damage in field experiment two represent escapes, because each plot that had rated $1 \%$ or lower in that experiment was checked to ensure there were no other diseased fruit in the plot that had been overlooked. Additionally, fruit in all the detached-fruit tests were placed directly on the inoculum.

Both PI 163216 and PI 197088 were segregating for fruit type, producing two types of fruit (round-netted, and oblong-warty). The most resistant segregates were selected from each cultigen for further testing. All other traits appeared stable except for some dwarf plant types observed in PI 163216. Clark and Block
(1984) reported in their published abstract that PI 165509, PI 197085, PI 197086, PI 197087, and PI 197088 had high resistance to belly rot. We did not test 197086, and rated PI 197088 resistant, but the other four accessions were not in our top resistance group.

Correlation analysis. The correlations between cultigens in the field and detached-fruit screening tests (Table 3 ) were calculated on the basis of the highest percentage infection over all rating dates for each test. The detachedfruit vs. field correlation was not statistically significant between detached-fruit test one and field screening test one (both conducted the same year). However, the correlation was significant between detached-fruit test two and field screening test two (both conducted the same year) (Table 3). The main differences between screening tests one and two were the improved rating procedure for the field experiment and the higher inoculum concentration used in test two, which may account for the higher correlation between detached-fruit and field data. It should be noted that, although significant, the correlations were low $(r=$ $0.50)$. Therefore, we concluded that it may be necessary to conduct both the field and detached-fruit tests, and choose cultigens with low ratings in both tests.

Table 2. The eight most-resistant and six most-susceptible cucumber cultigens to belly rot from the three laboratory (detached fruit) and two field studies. ${ }^{.}$

\begin{tabular}{|c|c|c|c|c|c|c|}
\hline \multirow[b]{3}{*}{ Cultigen name } & \multirow[b]{3}{*}{ Seed source } & \multicolumn{5}{|c|}{ Fruit surface infected $(\%)$} \\
\hline & & \multicolumn{3}{|c|}{ Detached-fruit screening } & \multicolumn{2}{|c|}{ Field screening } \\
\hline & & Initial screening & Test 1 & Test 2 & Test 1 & Test 2 \\
\hline \multicolumn{7}{|l|}{ Resistant } \\
\hline PI 163216 & India & 0 & 0 & 0 & 0 & 0 \\
\hline PI 197088 & India & 0 & 0 & 0 & 0 & 0 \\
\hline PI 357852 & Fmr. Yugoslavia & 0 & 0 & --- & 0 & --- \\
\hline PI 280096 & USSR & 0 & 0 & --- & 0 & --- \\
\hline PI 285606 & Poland & --- & 0 & --- & 0 & --- \\
\hline PI 271328 & India & 0 & 1 & 1 & 0 & 2 \\
\hline PI 379282 & Fmr. Yugoslavia & 0 & 3 & --- & 0 & --- \\
\hline \multicolumn{7}{|l|}{ Check cultigens } \\
\hline P 51 & Hollar Seed & 0 & --- & --- & 0 & --- \\
\hline Pioneer & Asgrow Seed & 0 & 1 & 1 & 0 & 2 \\
\hline Mariner & Harris Seed & 0 & --- & --- & --- & --- \\
\hline \multicolumn{7}{|l|}{ Susceptible } \\
\hline PI 344433 & Iran & --- & --- & 5 & 5 & --- \\
\hline PI 267741 & Japan & 2 & --- & 5 & 8 & --- \\
\hline PI 418962 & China & 4 & 9 & 0 & 6 & --- \\
\hline PI 177360 & Turkey & 5 & 9 & 10 & 1 & --- \\
\hline PI 169382 & Turkey & 8 & 12 & 6 & 12 & --- \\
\hline PI 419108 & Turkey & 8 & 15 & 6 & - & --- \\
\hline PI 181752 & Syria & 23 & 4 & --- & 10 & --- \\
\hline Mean & & --- & 3 & 3 & 3 & 4 \\
\hline LSD $_{005}$ & & --- & 7 & 7 & 9 & 7 \\
\hline $\mathrm{CV}$ & & --- & 126 & 84 & 115 & 76 \\
\hline
\end{tabular}

${ }^{2}$ Data represent the highest ratings measured in a given test.

Table 3. Correlations of fruit damage ratings in field and detached-fruit experiments conducted in North Carolina for resistance of cucumber to belly rot. ${ }^{2}$

\begin{tabular}{lccccc}
\hline & \multicolumn{3}{c}{ Fruit surface infected (\%) } \\
\cline { 2 - 3 } \cline { 5 - 6 } Trait & \multicolumn{2}{c}{ Detached-fruit } & & \multicolumn{2}{c}{ Field } \\
\cline { 2 - 3 } \cline { 5 - 6 } Screening test 1 (detached fruit) & Screening test 1 & Screening test 2 & & Screening test 1 & Screening test 2 \\
Screening test 2 (detached fruit) & $0.20^{*}$ & -- & --- & --- \\
Screening test 1 (field) & 0.07 & & --- & --- \\
Screening test 2 (field) & $0.30^{*}$ & $0.20^{*}$ & & --- & --- \\
\hline${ }^{2}$ All correlations based on the highest percent infection recorded over all rating dates for a given experi- \\
ment.
\end{tabular}
Fruit surface infected (\%) 


\section{Breeding, Cultivars, Rootstocks, \& Germplasm Resources}

Parmeter, J.E. (ed). 1970. Rhizoctonia solani: Biology and pathology. Univ. of Calif. Press, Berkeley.

SAS Institute. 1988. SAS/STAT user's guide, Release 6.03 edition. SAS Inst., Cary, N.C.

Sloane, J.T. and T.C. Wehner. 1984. Heritability of resistance to rhizoctonia fruit rot in a wide base cucumber population. Cucurbit Genet. Coop. Rep. 7:25-26.

Sloane, J.T., T.C. Wehner, and S.F. Jenkins, Jr. 1985.
Inheritance of resistance to Rhizoctonia fruit rot in cucumber. HortScience 20:1119-1120.

St. Amand, P.C. and T.C. Wehner. 1991. Crop loss to 14 diseases of cucumber in North Carolina from 1983 to 1988 . Cucurbit Genet. Coop. Rpt. 14:15-17.

Sumner, D.R and D.A. Smittle. 1976. Etiology and control of fruit rot of cucumber in single harvesting for pickles. Plant Dis. Rpt. 60:304-307.

Tuite, J. 1969. Plant Pathological methods-Fungi and bacteria. Burgess Pub. Co., Minneapolis.

Villajuan-Abgona, R., K. Kageyama, and M. Hyakumachi. 1996. Biocontrol of Rhizoctonia damping off of cucumber by non-pathogenic binucleate Rhizoctonia. European J. of Plant Path. 102:227-235.

Wehner, T.C. and M. Palmer. 1987. Aseedling test for resistance of cucumber lines to fruit rot caused by Rhizoctonia solani. Cucurbit Genet. Coop. Rpt. 10:31-32. 